\title{
Identification of Two Single Base Substitutions in the UGT1 Gene Locus Which Abolish Bilirubin Uridine Diphosphate Glucuronosyltransferase Activity In Vitro
}

\author{
Lorri T. Erps, Joseph K. Ritter, ${ }^{\ddagger}$ Joseph H. Hersh, * Donald Blossom, ${ }^{5}$ Nancy C. Martin, and Ida S. Owens ${ }^{*}$ \\ Department of Biochemistry and *Pediatrics, School of Medicine, University of Louisville, Louisville, Kentucky 40292; ${ }^{\ddagger}$ Human Genetics \\ Branch, National Institute of Child Health and Human Development, National Institutes of Health, Bethesda, Maryland 20892; and \\ ${ }^{\S}$ Children's Clinic, Los Alamos Medical Center, Los Alamos, New Mexico 87544
}

\begin{abstract}
Accumulating evidence indicates that mutations in the human UGT1 gene locus abolish hepatic bilirubin UDP-glucuronosyltransferase activity and cause the subsequent accumulation of bilirubin to toxic levels in patients with Crigler-Najjar type 1 (CN-I). Genetic and biochemical criteria are required to link CN-I with mutations in UGT1. Here we present analysis of mutations at the $U G T 1$ locus in three individuals that were clinically diagnosed with $\mathrm{CN}-\mathrm{I}$ ( two related and one unrelated). Each patient carries a single base substitution that alters conserved residues in the transferase enzyme molecule, serine to phenylalanine at codon 376 and glycine to glutamic acid at codon 309. Each was homozygous for the defect as demonstrated by sequencing and RFLPs. Mutant cDNAs, constructed by site-directed mutagenesis, inserted into expression vectors, and transfected into COS-1 cells, supported the synthesis of the bilirubin transferase protein but only cells transfected with the wild-type cDNA expressed bilirubin UDP-glucuronosyltransferase activity. The data provide conclusive evidence that alterations at Gly 309 and Ser 376 are the genetic basis for CN-I in these families. These results suggest that the two codons, located in conserved regions of the molecule, are part of the active site of the bilirubin enzyme. (J. Clin. Invest. 1994. 93:564570.) Key words: Crigler-Najjar type I • hyperbilirubinemia • restriction fragment length polymorphism - point mutation • DNA sequence analysis
\end{abstract}

\section{Introduction}

Bilirubin, the product of heme degradation, is a potentially lethal endogenous substance when present at high levels in the blood. Bilirubin UDP-glucuronosyltransferase (UDPGT) ${ }^{1}$

Portions of this work have appeared in abstract form (1993. FASEB (Fed. Am. Soc. Exp. Biol.) J. 7:1073a).

Address correspondence to Lorri T. Erps, Department of Biochemistry, School of Medicine, University of Louisville, Louisville, KY 40292 .

Accession numbers from GenBank are as follows: HUG-Br 1 cDNA (M57899), HUG-Br2 cDNA (M57951), UGT1 gene exon 2 (M84122), UGT1 exons 3 and 4 (M84123), UGT1 exon 5 (M84124), UGT1A exon 1 (A) (M84125), and UGT1D exon 1 (D) (M84128).

Received for publication 6 July 1993 and in revised form 10 September 1993.

1. Abbreviations used in this paper: $\mathrm{CN}-1$, Crigler-Najjar syndrome, type 1; TBS, Tris-buffered saline; UDPGA, $\left[{ }^{14} \mathrm{C}\right] \mathrm{UDP}$; UDPGT, UDP-glucuronosyltransferase.

J. Clin. Invest.

(c) The American Society for Clinical Investigation, Inc.

0021-9738/94/02/0564/07 \$2.00

Volume 93, February 1994, 564-570 conjugates one, then often a second, glucuronic acid molecule to the carboxyl groups of the propionate side chains of bilirubin ( $\mathrm{C}-8$ or $\mathrm{C}-12$ ), making it polar and therefore readily excreted in the bile (1). This enzyme is membrane bound, and its active site is located on the luminal side of the liver endoplasmic reticulum (2). Bilirubin UDPGT activity is not detected in patients with the autosomal recessive disorder Crigler Najjar, type I (CN-I) (3). Therefore, CN-I individuals have high serum bilirubin levels (at least $20 \mathrm{mg} / \mathrm{dl}$; normal $0.2-1.2 \mathrm{mg}$ / dl ) primarily unconjugated, which lead to deposition of bilirubin in the brain and nervous tissue. The majority of CN-I patients generally succumb in early childhood due to kernicterus (brain degeneration) (4), yet some live to early adulthood either with the aid of phototherapy and sequestering drugs or because of late onset of the disease. Liver transplantation which is now often performed on the $\mathrm{CN}-\mathrm{I}$ patients may further extend life expectancy (5). The less severe $\mathrm{CN}$ type II syndrome (6) is also characterized by high serum bilirubin levels of between 3 and $20 \mathrm{mg} / \mathrm{dl}$, but is distinguishable from CN-I by the presence of detectable bilirubin glucuronidating activity (indicated by the presence of bilirubin glucuronides in the bile). The latter is often discernible only after treatment with phenobarbital, an inducer of hepatic bilirubin UDPGT activity (6). A third type of unconjugated hyperbilirubinemia is Gilbert's syndrome (7), which affects $6 \%$ of the population and exhibits bilirubin levels of $0.8-3 \mathrm{mg} / \mathrm{dl}$ ( two- to sixfold above normal).

Bilirubin UDPGT activity arises from a gene complex of unusual structure (8) located on human chromosome $2(9)$. The complex, UGT1, actually consists of several nested and overlapping UDPGT transcription units (i.e., genes). Two of the transcription units ( $U G T 1 A$ and $U G T 1 D$ ) encode the UDPGT isoforms that have glucuronidating activity towards bilirubin ( the enzymes encoded by the cDNAs, HUG-Brl and HUG-Br2, respectively) (10). The remaining units encode isoforms with either unknown substrate specificity ( $U G T 1 C$ and $U G T 1 E$ ) or specificity for phenolic substrates (UGTIF and $U G T 1 G)(8,11)$. Like all $U G T 1$ transcription units, the bilirubin transferase genes ( $U G T 1 A$ and $U G T 1 D$ ) each have a unique promoter, $5^{\prime}$ flanking region, and exon 1 (encoding the unique amino terminus of each encoded UDPGT), whereas exons 2-5 (the common exons) located at the extreme 3 ' terminus of the locus are shared by all units. Since exons $2-5$ code for the final 246 amino acids (or approximately half) of each UDPGT polypeptide, all isoforms produced by the complex have identical carboxyl termini. Although the genes overlap, they are independently regulated because of their unique promoters, as seen by their tissue-specific patterns of expression and their differential expression before and after phenobarbital treatment (10). In human liver, $U G T 1 A \mathrm{mRNA}$ is fourfold more abundant than that of $U G T 1 D$, and transcription of $U G T I D$ appears to be selectively responsive to phenobarbital (10). 
Given the complexity of the locus, familial hyperbilirubinemias arising from defects in the enzymes coded by UGTI could have many different possible bases, including mutations affecting the transcription or processing of primary transcripts. However, the relationship between the bilirubin UDPGT transcription units $U G T 1 A$ and $U G T 1 D$ suggests that mutations in one of the common exons are the most frequent cause for the complete loss of bilirubin UDPGT activity in patients with $\mathrm{CN}-\mathrm{I}$. This appears to be supported by the data so far available concerning sequence alterations in $U G T 1$ associated with $\mathrm{CN}$ I. These alterations include a 13-base frameshift deletion in exon 2 (12), and point mutations in exons 2 (13) and $3(14)$. For all of the mutations, especially in cases where the suspected mutation is a potentially silent mutation, both biochemical and genetic criteria are required to associate a given mutation in $U G T I$ with the inactivation of bilirubin UDPGT and the onset of CN-I disease. Continued analysis of the molecular basis of CN-I in different patients should further our understanding of the structure-function relationships of the various transferases encoded by this gene.

To that end, we have analyzed the $U G T I$ locus in two separate families with children clinically diagnosed with $\mathrm{CN}-\mathrm{I}$. Diagnosis was based on serum bilirubin levels of $30-41 \mathrm{mg} / \mathrm{dl}$ (primarily unconjugated) and the lack of any significant reduction in blood levels of the heme derivative after phenobarbital administration. We hypothesized that the cause of the unconjugated hyperbilirubinemia in the affected children from both families was due to a genetic defect in one or more of the common exons of the bilirubin UDPGT gene. PCR amplification of genomic DNA and analysis of the subclones revealed mutations that affect residues that are highly conserved in bilirubin and other UDPGT isozymes, Gly 309 and Ser 376. Expression studies comparing the activities of wild-type and mutant cDNA-encoded proteins demonstrated that each mutation can independently abolish HUG-Brl enzyme activity.

\section{Methods}

CN-I patient diagnoses and histories. N.H. is a 13-yr-old white female who was the product of a third cousin mating developed unconjugated hyperbilirubinemia on day 2 of life, reaching a level of $13 \mathrm{mg} / \mathrm{dl} 2 \mathrm{~d}$ later. Jaundice progressed, and total bilirubin reached $20 \mathrm{mg} / \mathrm{dl}$ by $5 \mathrm{yr}$ of age, despite phototherapy and phenobarbital treatment. A liver biopsy did not reveal histologic abnormalities, and a presumed diagnosis of Crigler-Najjar syndrome was made. Because of a continued rise in unconjugated hyperbilirubinemia $(40 \mathrm{mg} / \mathrm{dl}$ by $10 \mathrm{yr}$ ) and the continued absence of any neurological sequelae, liver transplantation was performed at $12.5 \mathrm{yr}$ of age. Transplantation of the left lateral segment of her father's liver was unsuccessful, but a second partial liver transplantation from a cadaver donor was successful. The bilirubin levels fell precipitously, and she remains neurologically normal. There was no detectable bilirubin UDPGT activity in a sample of her liver obtained at the time of surgery (Odell, G., personal communication).

Her male first cousin, T.C., an 11 -yr-old white male whose parents were also consanguineous, developed early onset unconjugated hyperbilirubinemia, which reached a level of $11.7 \mathrm{mg} / \mathrm{dl}$ on day 4 of life. At 4 yr of age a liver biopsy revealed hepatic histology indicative of CN-I. At $10 \mathrm{yr}$ of age his bilirubin level had reached $30-40 \mathrm{mg} / \mathrm{dl}$.

The affected member of the second family analyzed, M.L., was also the offspring of consanguineous parents. M.L. is a 7-yr-old female CN1 patient. $2 \mathrm{~d}$ after birth, jaundice appeared, and the total bilirubin concentration in serum was $13.6 \mathrm{mg} / \mathrm{dl}$. Blood tests showed that the mother was $\mathrm{O}+$, and the baby was $\mathrm{B}+$. Although an initial Coombs' test was positive, subsequent tests proved negative. There was no hemolysis. The patient had normal liver function as indicated by serum activities for alkaline phosphatase, lactate dehydrogenase, serum glutamic-oxaloacetic transaminase, and gamma-glutamyl transpeptidase. Total serum bilirubin concentrations averaged $24-27 \mathrm{mg} / \mathrm{dl}$ and did not decrease by treatment with phenobarbital $(10 \mathrm{mg}$, twice daily). During periods of illness, bilirubin concentrations rose into the $30 \mathrm{~s}$, with a peak level of $31.7 \mathrm{mg} / \mathrm{dl}$. Analysis of serum and bile for the presence of bilirubin glucuronides was negative. The patient has exhibited normal growth and neurologic development.

Polymerase chain reaction and sequencing of UGTI common exons. Genomic DNA was isolated from blood samples of affected individuals and relatives in both families as described previously (12). For the analysis of the common UGTI exons 2-5 in the two unrelated families, two slightly differing strategies were used. The analysis of M.L. and her family was carried out using the strategy reported previously for the analysis of $U G T 1$ in $\mathrm{CN}-1$ patient F.B., and five subclones of exon 2 derived from the genomic DNA of M.L. were sequenced (12). For the analyses of the patients N.H. and T.C. and their families, at least six separate rounds of asymmetric PCR were followed by direct sequencing and used the primers described by Ritter et al. (12). Briefly, the primer pairs, PXG3 with PXG4, PXG5 with PXG6, PXG7 with PXG8, and PXG9 with PXG10, flank exons 2, 3, 4, and 5, respectively, in the intron regions. The 50- $\mu$ asymmetric PCR reaction contained 1 $\mu \mathrm{g}$ of genomic DNA, a primer pair ( $10 \mathrm{pmol}$ of the upstream primer and $500 \mathrm{pmol}$ of the downstream primer), $10 \mathrm{mM}$ Tris- $\mathrm{HCl}, \mathrm{pH} 8.3$, $50 \mathrm{mM} \mathrm{KCl}, 1.5 \mathrm{mM} \mathrm{MgCl}_{2}, 0.001 \%$ (wt/vol) gelatin, $0.2 \mathrm{mM}$ each $\mathrm{dNTP}$, and $1.5 \mathrm{U}$ of DNA polymerase (Amplitaq; Cetus Corp., Emeryville, CA). The reaction mixtures were overlaid with $30 \mu \mathrm{l}$ mineral oil, and were subjected to 25 cycles of $94^{\circ} \mathrm{C}$ for $1 \mathrm{~min}, 60^{\circ} \mathrm{C}$ for $1.5 \mathrm{~min}$, and $72^{\circ} \mathrm{C}$ for $3 \mathrm{~min}$ with a final extension time of $30 \mathrm{~min}$. Nondenaturing PAGE was used to confirm that the correct size PCR product was made. The DNA was separated from primers and unincorporated nucleotides by chromatography on a $100-\mu$ l bed of Sephacryl S-300 (Pharmacia LKB Biotechnology Inc., Piscataway, NJ), which was equilibrated with $10 \mathrm{mM}$ Tris- $\mathrm{HCl}, \mathrm{pH} 7.6$, and $0.1 \mathrm{mM}$ EDTA, and then was centrifuged twice at $1,700 \mathrm{~g}$ for $2 \mathrm{~min}$. The double-stranded DNA concentration of the eluent was measured by fluorometry. Dideoxy DNA sequencing was done using the TaQuence kit (United States Biochemical Corp., Cleveland, $\mathrm{OH}$ ). A modification of the protocol using the thermal cycler was carried out (15). The samples were electrophoresed on a $6 \%$ sequencing gel that was fixed in $15 \%$ methanol and $5 \%$ acetic acid, dried, and exposed to x-ray film. We sequenced both strands of the DNA and compared the sequence to the published human bilirubin UDPGT cDNA sequence (10).

RFLP analysis. For the rapid screening of carriers and further confirmation of the mutations identified in exon 4 of N.H. and T.C. $(\Delta 376)$ and exon 2 of M.L. $(\Delta 309)$, DNA fragments encompassing the mutation were amplified by PCR using the primer pairs described above. Afterwards, samples of the PCR reaction were directly digested with either NlaIV (N.H., T.C., and their families) or Sau3A I (M.L. and her family) and were analyzed by nondenaturing PAGE with ethidium bromide staining.

Site-directed mutagenesis of HUG-Brl cDNA. An oligonucleotidedirected PCR method (16) was used to introduce the $C \rightarrow T$ mutation at the second position of codon 376 or the $G \rightarrow$ A mutation at the second position of codon 309 into restriction fragments which were then exchanged with the same fragment from the wild-type pHUG-Br 1 expression vector (10). These corresponded to a 325-bp BstEII-BssHII fragment or a 378-bp XmnI-BstEII fragment, respectively. The resulting mutant expression vectors, pHUG-Br1-Phe376 and pHUG-Br1Gly309, are identical to the wild-type expression vector pHUG-Brl except for specified codon alteration.

Bilirubin UDPGT activity assays of COS-1 cell-derived enzyme. COS- 1 cells were grown in plates with $10 \mathrm{ml}$ DME with $4 \%$ FCS to $80 \%$ confluency for $1 \mathrm{~d}$ at $37^{\circ} \mathrm{C}$ under $\mathrm{CO}_{2}$. After two washes with TBS, serum-free DME in Hepes was added to each plate along with $25 \mu \mathrm{g}$ of cesium chloride-purified plasmid mixed with $0.5 \mathrm{ml}$ TBS and $0.16 \mathrm{ml}$ 
of $100 \mathrm{mg} / \mathrm{ml}$ DEAE-dextran in TBS. Plates were incubated as above for $3 \mathrm{~h}$ and were washed twice with TBS. Then $10 \mathrm{ml}$ of media with 200 $\mu \mathrm{g} / \mathrm{ml}$ of chloroquine was added, and the incubation continued at $37^{\circ} \mathrm{C}$ for $2-3 \mathrm{~h}$ until large vacuoles had formed. The cells were washed twice with TBS and were incubated for $3 \mathrm{~d}$ in $15 \mathrm{ml}$ of DME-4.

Microsomes $(0.115 \mathrm{mg})$ and cell homogenates from the transfected cells $(0.25 \mathrm{mg}$ protein $)$ were assayed for bilirubin UDPGT activity by a modified unified assay of Bansal and Gessner (17). A 100- $\mu$ l reaction mixture containing $16 \mathrm{mM}$ sodium phosphate, $\mathrm{pH} 7,\left[{ }^{14} \mathrm{C}\right]$ UDP glucuronic acid (UDPGA) $(0.02 \mu \mathrm{Ci} / \mu \mathrm{l})$ with nonradioactive UDPGA, 5 $\mathrm{mM} \mathrm{MgCl}$, and $200 \mu \mathrm{M}$ bilirubin in DMSO was incubated for 2 ( $\mathrm{mi}-$ crosomes) or $16 \mathrm{~h}$ (cell homogenates) in the dark at $37^{\circ} \mathrm{C}$. The final $\mathrm{pH}$ was checked before incubation and was adjusted to 6.4 (Ritter, J. K., M. T. Yeatman, C. Kaiser, B. Gridelli, and I. S. Owens, manuscript submitted for publication) or 7.6. Microsomes and cell homogenates were preactivated with $0.5 \mathrm{mg} 3$-[(3-cholamidopropyl)dimethylammonio]-1-propanesulfonate detergent per milligram of protein. All incubations were flushed with nitrogen, sealed, and incubated in the dark for $16 \mathrm{~h}$ at room temperature. The reactions were terminated by adding $200-\mu \mathrm{l}$ ethanol and were stored at $-70^{\circ} \mathrm{C}$ until analyses were performed.

The reaction mixtures were centrifuged for $10 \mathrm{~min}$, and the supernatant was dried in a lyophilizer in the dark. A $30-\mu$ l aliquot of chloroform was added to the dried supernatant and was applied to the bottom of a precoated silica gel preparative TLC plate (Pierce Chemical Co., Rockford, IL). The TLC plate was developed (17), and then the dried plates were analyzed for activity by colorimetric observation ( Radioanalytical Imaging Mark II system; AMBIS, Inc., San Diego, CA) before exposure to $\mathrm{x}$-ray film.

Immunoprecipitation of newly synthesized protein in COS-1 cells. Radiolabeling of newly synthesized protein in COS- 1 cells was followed by a single antibody immunoprecipitation. COS-1 cells were transfected as described above and were incubated $3 \mathrm{~d}$. During the last $5 \mathrm{~h}$ of culture, the cells were treated as follows. Starving media $\left(3 \mathrm{ml} / 25 \mathrm{~cm}^{2}\right.$ flask ) without methionine were added, and cells were incubated for $1 \mathrm{~h}$ at $37^{\circ} \mathrm{C}$. Labeling media $(1 \mathrm{ml} /$ flask $)$ with $\left[{ }^{35} \mathrm{~S}\right]$ methionine, penicillin/streptomycin, and glutamine were added, and cells were shaken every $20 \mathrm{~min}$ for 3-4 h. Labeling was stopped by the addition of 50 $\mu \mathrm{l} /$ flask of $10 \mathrm{mg} / \mathrm{ml}$ of cold methionine, $10 \mu \mathrm{l}$ of $50 \mathrm{mg} / \mathrm{ml}$ trypsin inhibitor, and $1 \mathrm{ml}$ of lysis solution ( $1 \%$ Triton X-100, 0.5\% Na-deoxy- cholate, $0.1 \%$ SDS, 1 mM EDTA, pH 7, 0.02\% Na-azide, $1 \times$ PBS. Cell lysates were stored at $-70^{\circ} \mathrm{C}$. After thawing, the lysed cellular material was centrifuged at $12,000 \mathrm{rpm}$ for $15 \mathrm{~min}$, and to each supernatant (transferred to a fresh tube) was added $5 \mu$ l of goat anti-mouse UDPGT immunoglobulin and processed according to Mackenzie et al. (18) for autofluorography.

\section{Results}

To test the hypothesis that affected members of the two different families have an alteration in the gene coding for bilirubin UDPGT, we sequenced exons 2-5 of UGT1. Affected individuals in each family did have an alteration, but the alterations were in different exons. For the two CN-I children in the first family, exons 2, 3, and 5 were normal (data not shown), but exon 4 contained a $\mathrm{C} \rightarrow \mathrm{T}$ base change at the second position of codon 376 (Fig. 1). This confirms the results of Bosma et al. (13) who sequenced the genomic DNA isolated from liver samples taken at the time of N.H.'s liver transplant. The results with DNA from T.C. extend and further confirm the finding in N.H. The nucleotide substitution is located 40 bases from the intron 3 /exon 4 junction. An examination of the sequence obtained from the mother of N.H. showed a signal in both the $\mathrm{C}$ and $\mathrm{T}$ lanes at this position in exon 4 (data not shown), indicating heterozygosity at this locus. The sister of N.H. has a signal only in the $\mathrm{C}$ lane and is thus homozygous normal (Fig. 1).

The affected individual from the second family, M.L., had a normal sequence for exons 3, 4, and 5, but her exon 2 had a $\mathrm{G} \rightarrow$ A base change at the second position of codon 309 (Fig. 1). This mutation is located 55 bases from the exon 2 /intron 2 junction.

A single restriction site for NlaIV (GGNNCC) in the exon 4 PCR product is abolished by the $\mathrm{C} \rightarrow \mathrm{T}$ mutation and the resulting sequence, GGTTTC. A 309-bp product correspond-
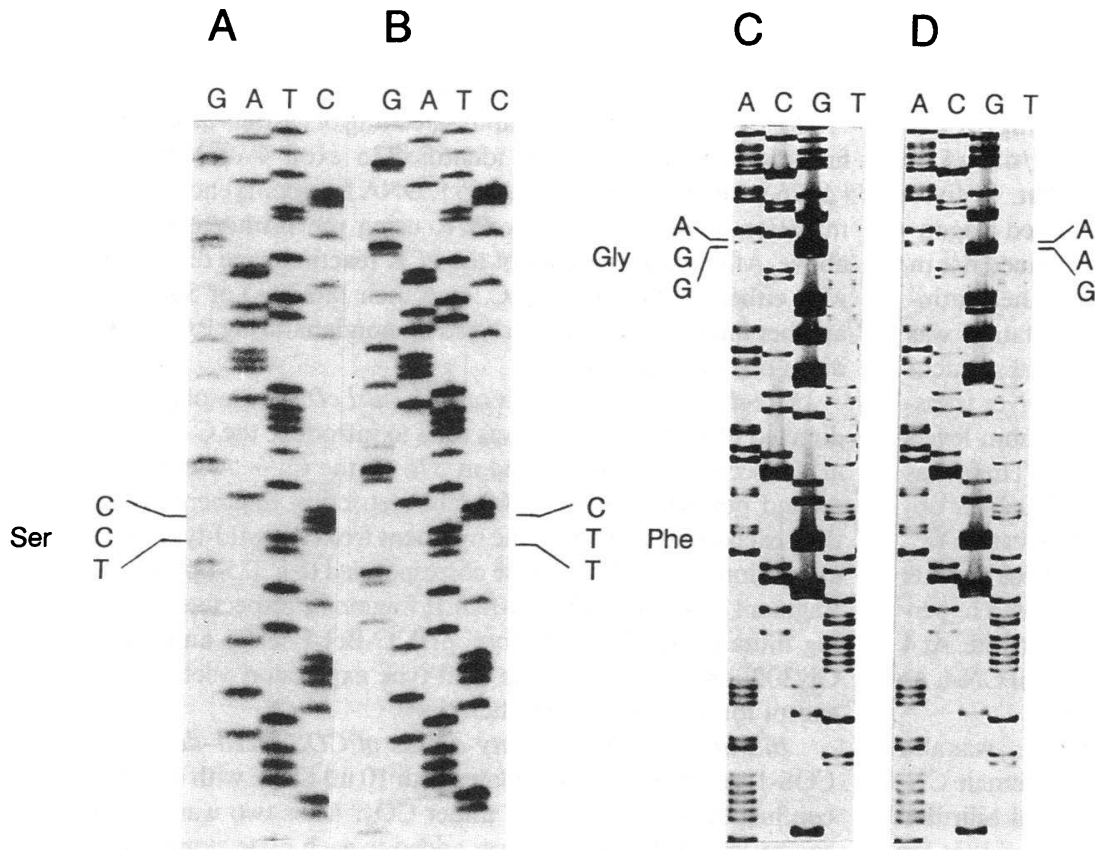
Figure 1. Single base substitutions in the coding sequence of $U G T 1$ in two unrelated $\mathrm{CN}-\mathrm{I}$ patients. Genomic DNA was ampli- fied and was sequenced as described in Methods. $A$ and $B$ are partial sequence lad- ders corresponding to $U G T 1$ exon 4 from a normal individual $(A)$ and the $\mathrm{CN}-1$ pa- tient N.H. $(B)$. The $\mathrm{C} \rightarrow \mathrm{T}$ base change shown corresponds to the second position of codon 376 , and is predicted to change serine to phenylalanine in all UGT1-en- coded UDPGTs, including the primary bil- irubin UDPGT isoform, encoded by the HUG-Brl cDNA. $C$ and $D$ show a partial sequence of $U G T I$ exon 2 from a normal individual $(C)$ and the patient M.L. $(D)$. The $G \rightarrow$ A alteration changes the residue encoded by codon 309 from glycine to glu- tamic acid. $G, A, T$, and $C$ are lanes corre- sponding to separate reactions with added dideoxy derivatives of GTP, ATP, TTP, and CTP, respectively.




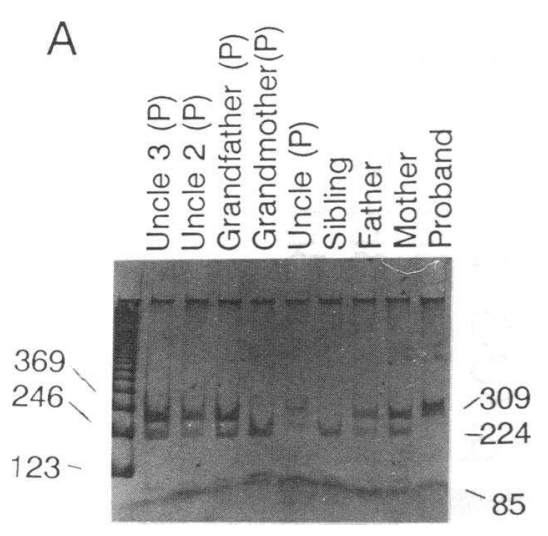

Figure 2. Restriction analysis of exon 4 PCR products amplified from genomic DNA from the extended family of N.H. $(A)$ and T.C. $(B)$. Samples of PCR reactions were generated from genomic DNA $(1 \mu \mathrm{g})$, were digested with NlaIV, and were analyzed by electrophoresis through a $5 \%$ nondenaturing polyacrylamide gel as described in Methods. DNA from homozygous normal individuals generates a 224- and a 85bp fragment (faint), while DNA from homozygous $\mathrm{CN}$-1-affected patients generates an undigested 309-bp fragment. DNA from heterozygous carriers generates equimolar amounts of all three fragments. Nucleic acid size markers (in bp) are shown at the sides of each figure. $P$, paternal. $M$, maternal. ing to the wild-type allele yields a 224- and a 83-bp fragment when digested with NlaIV. The 309-bp PCR product made from a mutant allele is not digested with this enzyme. Therefore, carriers possess the 309-bp fragment from the mutant allele and the 224-bp fragment from the normal allele. DNA from the family of N.H. and T.C. were screened using the RFLP technique (Fig. 2). From this analysis, it is clear that both sets of parents were carriers as were the paternal grandfather of N.H., and the paternal grandfather and the maternal grandmother of T.C. This pattern is the expected result if the $\mathrm{C} \rightarrow \mathrm{T}$ change is coinherited with the disease. There was no DNA available for the maternal grandparents of N.H.

The $\mathrm{G} \rightarrow$ A mutation in the second family is predicted to eliminate a restriction site for the enzyme Sau3AI (GATC to AATC). Normal DNA corresponding to a 311-bp fragment,
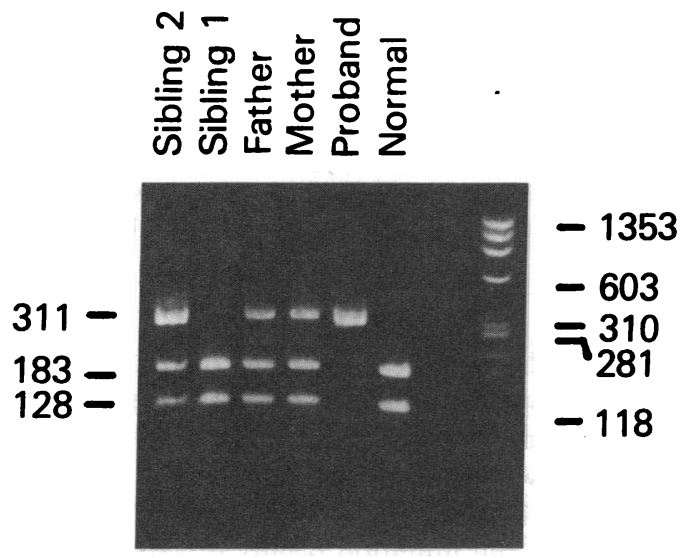

Figure 3. Restriction enzyme analysis of exon 2 PCR products amplified from genomic DNA from the immediate family of M.L. Analysis was performed as described in the legend to Fig. 2, except that exon 2 was amplified (by primers PXG3 and PXG4) and the products were digested with Sau $3 \mathrm{AI}$. The analyses included samples corresponding to the proband, each of her parents, two siblings, and a normal individual. The normal allele generates two Sau3AI fragments of 183 and $128 \mathrm{bp}$ in length, while the mutant allele yields an undigested 309-bp fragment. A standard with known molecular weight markers (in bp) is shown at the right. which encompasses exon 2 and is amplified by the primers PXG3 and PXG4, is digested at one site by Sau3AI, yielding two fragments of 183-and 128-bp (Fig. 3). The mutant allele is predicted to lack the Sau3AI site. Fig. 3 shows the results of a Sau3AI analysis of DNA of the proband M.L. and her family. The results indicate that M.L. is a homozygote for the $G \rightarrow A$ base change at codon 309, whereas her parents and one sibling (sibling 2 in Fig. 3 ) are heterozygotic. The remaining sibling (sibling 1 ) is homozygous for the normal allele.

To determine whether the alterations in the UGTI gene lead to alterations in enzyme activity, we constructed mutant HUG-Brl expression plasmids containing either the $\mathrm{C} \rightarrow \mathrm{T}$ mutation at codon 376 (pHUG-Br1-Phe376) or the $\mathrm{G} \rightarrow \mathrm{A}$ mutation at codon 309 (pHUG-Br1-Glu309). pHUG-Br1Phe376 and pHUG-Br1-Glu309 are identical to the normal HUG-Brl expression unit, pHUG-Brl (10), with the exception of the designated single base substitution. For controls, constructs with the orientation of insert reversed with respect to the SV40 promoter were used. The normal pHUG-Br1 unit or mutant expression constructs were transfected into COS-1 cells. Bilirubin UDPGT activity was detectable in either human microsomes or homogenates of COS- 1 cells transfected with the wild-type pHUG-Brl expression plasmid. For the pHUG-Br1-transfected cells, activity was higher when the assay was performed at pH 6.4 than at pH 7.6 (Ritter, J. K., M. Yeatman, C. Kaiser, and I. S. Owens, manuscript submitted for publication ). No expression of activity was detected in cells transfected with pHUG-Br1-Phe376 and pHUG-Br1-Glu309, regardless of the orientation of the cDNA or the pH (Fig. 4).

If the alteration destabilizes the protein, then the lack of enzyme activities could be because of a lack of enzyme protein. Alternatively, the mutation could affect the ability of the enzyme to carry out the glucuronidation of bilirubin without altering protein levels. To distinguish between these two possibilities, transfected COS-1 cells were grown in radiolabeled media, and bilirubin UDPGT protein was immunocomplexed and was trapped with protein A-Sepharose (Sigma Immunochemicals, St. Louis, MO). The same size and amount of the protein was produced in cells with normal or mutant HUG-Br 1 cDNA in the correct orientation (Fig. 5). No protein was synthesized in cells that were transfected with the expression plasmids containing the mutant cDNAs in the reverse orientation (Fig. 5). 

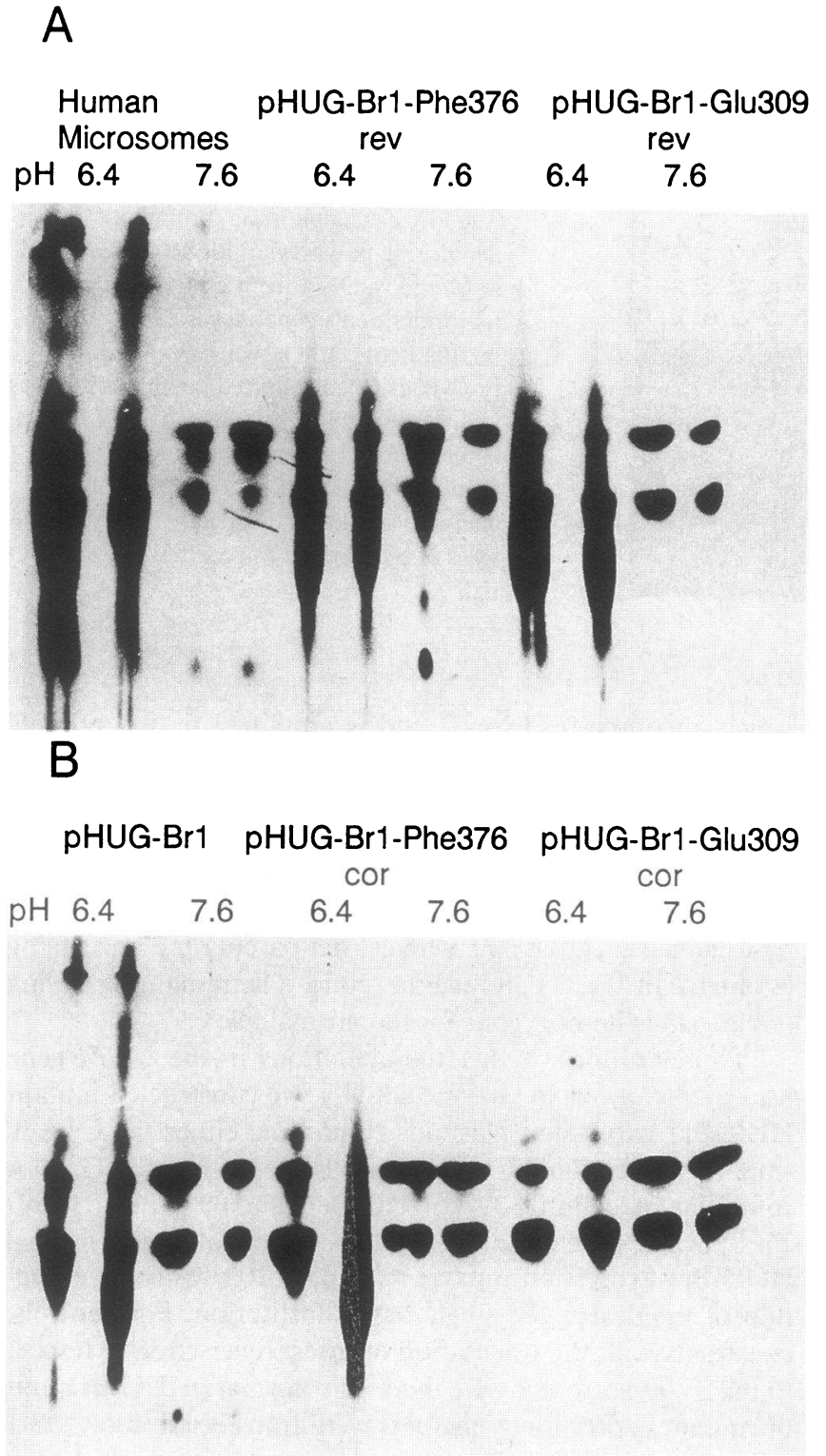

Figure 4. Assay of bilirubin activity generated by wild-type or the mutants of pHUG-Brl encoding either Phe 376 or Glu 309 expressed in transfected COS-1 cells. Bilirubin UDPGT activity was assayed using $\left[{ }^{14} \mathrm{C}\right]$ UDPGA as described in Methods at either $\mathrm{pH} 7.6$ or 6.4. After TLC to separate bilirubin glucuronides from unreacted UDPGA (and intermediates), the plate was exposed to $x$-ray film to give the autoradiogram shown. The source of the sample and the $\mathrm{pH}$ used for the activity determination are shown above each sample. The first four lanes in each panel are positive controls corresponding to bilirubin UDPGT activity in either human microsomes $(A)$ or after expression in COS-1 cells after transfection with the normal pHUG-Brl expression unit $(B)$. The faster migrating material near the tops of these lanes corresponds to glucuronide conjugates of bilirubin. The products are not observed in reactions using cells expressing the mutant versions of HUG-Brl (pHUGBr1-Phe376, middle four lanes of $A$ and $B$; and pHUG-Brl-Glu309, right four lanes of $A$ and $B$ ).

\section{Discussion}

We have identified two separate point mutations and have shown directly that each causes a defect in bilirubin UDPGT
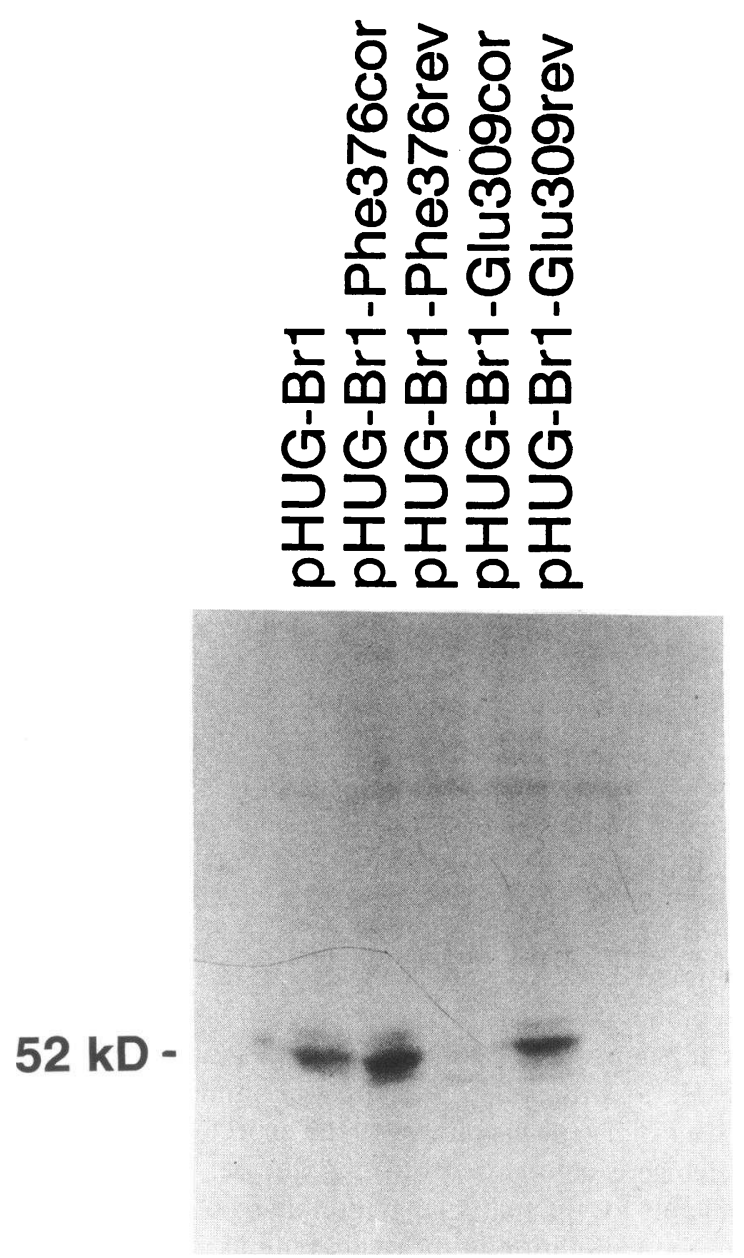

Figure 5. Production of bilirubin UDPGT protein from wild-type and mutant pHUG-Brl expression plasmids in COS-1 cells. Immunoprecipitates of extracts from transfected COS- 1 cells, which were $\left[{ }^{35} \mathrm{~S}\right]-$ methionine labeled and were immunocomplexed with specific antibody, were prepared and analyzed by SDS-PAGE as described in Methods. The gel was dried and exposed to $\mathrm{x}$-ray film for $7 \mathrm{~d}$ to give the autoradiogram shown. Approximately equal amounts of a 52-kD product corresponding to the mature, glycosylated HUG-Brl-encoded isoform were obtained from COS-1 cells transfected with the wild-type or mutant expression constructs (containing the cDNA in the correct orientation for expression). The molecular mass of the HUG-Brl-encoded protein has been shown to be $52 \mathrm{kD}(10)$.

activity. The rare incidence of this autosomal recessive disease is usually associated with consanguineous mating of parents, presumably heterozygotes for the same mutation. Such is the case for each of the two families studied here. A C $\rightarrow T$ base change was present in both alleles of two related children with CN-I, N.H. and T.C. The mutation occurs in exon 4 of the UGTl gene and produces a mutant version of HUG-Brl which contains phenylalanine instead of serine at amino acid 376 . Bosma et al. (13) found a moderately decreased level of bilirubin UDPGT protein in the liver microsomes of N.H. while activity of the enzyme was absent. Our studies extend the observations of Bosma et al. (13) by demonstrating the presence of the same alteration in T.C. and the pattern of inheritance as predicted for a mutation responsible for an autosomal recessive disease in this family. Further we demonstrate that the muta- 
tion in the cDNA alone abolishes enzyme activity when expressed in cell culture.

In addition, we have identified a second, different point mutation in an unrelated $\mathrm{CN}-1$ patient, M.L., which results in the substitution of a glutamic acid residue for glycine at position 309 of the HUG-Brl-encoded bilirubin isozyme, also resulting in inactivation of enzyme activity.

RFLPs associated with each mutation permitted an analysis of the family for inheritance patterns of the affected allele. Before pursuing the bilirubin activity assays, we were able to determine by the inheritance pattern of both RFLPs that each defect was a candidate for the cause of $\mathrm{CN}-1$. In the first family, an NlaIV RFLP allowed us to rapidly screen the DNA from blood samples of the extended family ( 30 individuals). In the second family, a Sau3AI RFLP allowed us to identify one of her siblings as a carrier. The NlaIV and Sau3AI RFLPs can be used for screening the respective families to identify carriers of the defect.

Extrapolation of the results with the COS-1 cells transfected with the mutant HUG-Brl expression constructs containing the $\mathrm{C} \rightarrow \mathrm{T}$ or $\mathrm{G} \rightarrow$ A mutations at codons 376 and 309 , respectively, to the in vivo situation suggests that these alterations are the cause of CN-I in N.H. and T.C. in the first family and M.L. in the second family. The activity of the other bilirubin UDPGT isoform, HUG-Br2, is likely affected as well since it has identical sequence in exons $2-5$. This is supported by the fact that HUG-Br2 is inducible by phenobarbital (10), and these patients did not respond to oral phenobarbital administration. The activities of the two phenol UDPGT isoforms expressed at this locus are also presumed to be affected by the location of the mutations in the common exons for these enzymes. Indeed, N.H. has been shown to have reduced hepatic microsomal activity toward 4-nitrophenol and 4-methylumbelliferone (13). A partial rather than complete loss of phenol glucuronidating activities in N.H. is due to the existence of other UDPGT genes at unlinked loci that encode isoforms active towards phenolic substrates, possibly the testosterone isoform (19).

Both of the point mutations are predicted to result in the alteration of highly conserved residues in the protein sequence of the HUG-Brl-encoded (and other UGT1-encoded) isoform(s). The $\mathrm{C} \rightarrow \mathrm{T}$ base change at the second position of codon 376 in HUG-Brl results in a nonconservative substitution of phenylalanine for a serine. This serine codon is conserved in four rat UDPGT genes (three steroid and the bilirubin/phenol UDPGT gene), and the mouse bilirubin/phenol UDPGT gene. The small polar serine is replaced by a small nonpolar alanine in three other rat UDPGTs and one other mouse UDPGT (data not shown). This suggests the need for a small amino acid residue at position 376 of HUG-Brl rather than a large, bulky, hydrophobic residue, like phenylalanine. The glycine at position 309 is absolutely conserved in all UDPGT sequences reported to date. It is part of a larger, highly conserved domain extending from positions 298-315, represented by the sequence Ser-Gly-(Glu / Asp)-(His/Asn)-Gly(Ile / Val )-Val-Val-Phe-Ser-Leu-Gly-Ser-Met-( Val/Ile)-Ser(Glu/Asn)-(Ile/Met) (GenBank M84122). At least 95\% conservation is observed in the identity of these 18 amino acids in the bilirubin/phenol or steroid UDPGTs reported so far in the GenBank/EMBL database for the rat, mouse, or human. Its function is unknown.
In the transferases produced by $U G T 1$, exons 2-5 are believed to encode the UDPGA binding site. This carboxyl terminus is highly conserved across species in that the rat and human bilirubin UDPGT isoforms are 90\% identical (10). The active site residues in the bilirubin UDPGT enzymes are not yet known. However, chimeric studies show that the catalytic site in two human bile acid/steroid UDPGTs have nine amino acid residues between 385 and 469 which are important for catalytic efficiency (20). This may correspond to a similar active site region in bilirubin UDPGT including $\mathrm{Ser}^{376}$.

The $U G T I$ locus encodes transferases which glucuronidate various aglycone substrates. $\mathrm{CN}-1$ patients possess a variety of phenotypes for deficiencies in glucuronidation of these substrates $(21)$. We now know this is because of a variety of mutations in different families (22). Our study, for the first time, shows regions of the bilirubin transferase molecule that are critical for activity and, therefore, are likely to be part of the active site of the isoform. Further observations of new mutations along with the corresponding phenotype may help us to uncover other critical amino acid residues at this gene locus.

\section{Acknowledgments}

We thank Dr. Peter Whitington of the Wyler Childrens Hospital, University of Chicago, Chicago, IL for the liver samples he generously gave us. We thank Dr. Gerard Odell at the University of Wisconsin, Madison for the insightful discussions and communications of his results. We also thank Sarah Mosier for her technical assistance in preparing the mutant plasmids.

Lorri T. Erps was supported by the Alliant Community Trust Fund, Louisville, Kentucky.

\section{References}

1. Ostrow, J. D., and N. H. Murphy. 1970. Isolation and properties of conjugated bilirubin and bile. Biochem. J. 120:311-327.

2. Vanstapel, F., and N. Blanckaert. 1987. Endogenous esterification of bilirubin by liver microsomes. J. Biol. Chem. 262:4616-4623.

3. Crigler, J. F., and V. A. Najjar. 1952. Congenital familial non-hemolytic jaundice with kernicterus. Pediatrics. 10:169-180.

4. Roy Chowdhury, J., A. W. Wolkoff, and I. M. Arias. 1989. Hereditary jaundice and disorders of bilirubin metabolism. In The Metabolic Basis of Inherited Disease. 7th ed. C. R. Scriver, A. L. Beaudet, W. S. Sly, and D. Valle, editors. McGraw-Hill Inc., New York. 1367-1408.

5. Kaufman, S. S., R. P. Wood, B. W. Shaw, R. S. Markin, P. Rosenthal, B. Gridelli, and J. A. Vanderhood. 1986. Orthotopic liver transplantation for type I Crigler-Najjar syndrome. Hepatology. 6:1259-1270.

6. Arias, I. M., L. M. Gartner, M. Cohen, J. Ben Ezzer, and A. J. Levi. 1969. Chronic nonhemolytic unconjugated hyperbilirubinemia with glucuronyltransferase deficiency: clinical, biochemical, pharmacologic, and genetic evidence for heterogeneity. Am. J. Med. 47:395-409.

7. Gilbert, A., and P. Lereboullet. 1901. La cholemia simple familiale. Sem. Med. 21:241-245.

8. Ritter, J. K., F. Chen, Y. Y. Sheen, H. M. Tran, S. Kimura, M. T. Yeatman, and I. S. Owens. 1992. A novel complex locus $U G T I$ encodes human bilirubin. phenol, and other UDP-glucuronosyltransferase isozymes with identical carboxyl termini. J. Biol. Chem. 267:3257-3261.

9. Harding, D., S. J. Jeremiah, S. Povey, and B. Burchell. 1990. Chromosomal mapping of a human phenol UDP-glucuronosyltransferase, GNTI. Ann. Hum. Genet. 54:17-21.

10. Ritter, J. K., J. M. Crawford, and I. S. Owens. 1991. Cloning of two human liver bilirubin UDP-glucuronosyltransferase cDNAs with expression in COS-1 cells. J. Biol. Chem. 266:1043-1047.

11. Wooster, R., L. Sutherland, T. Ebner, D. Clarke, O. Da Cruz e Silva, and B. Burchell. 1991. Cloning and stable expression of a new member of the human liver phenol/bilirubin:UDP-glucuronosyltransferase cDNA family. Biochem. $J$. 278:465-469.

12. Ritter, J. K., M. T. Yeatman, P. Ferreira, and I. S. Owens. 1992. Identification of a genetic alteration in the code for bilirubin UDP-glucuronosyltransfer- 
ase in the $U G T I$ gene complex of a Crigler-Najjar type I patient. J. Clin. Invest. 90:150-155.

13. Bosma, P. J., J. Roy Chowdhury, T. Huang, P. Lahiri, R. P. J. Oude Elferink, H. H. G. van Es, M. Lederstein, P. F. Whittington, P. L. M. Jansen, and N. Roy Chowdhury. 1992. Mechanisms of inherited deficiencies of multiple UDP-glucuronosyltransferase isoforms in two patients with Crigler-Najjar syndrome, type I. FASEB (Fed. Am. Soc. Exp. Biol.) J. 6:2859-2863.

14. Bosma, P. J., N. Roy Chowdhury, B. G. Goldhoorn, M. H. Ho fker, R. P. J. Oude Elferink, P. L. M. Jansen, and J. Roy Chowdhury. 1992. Sequence of exons and the flanking regions of human bilirubin-UDP-glucuronosyltransferase gene complex and identification of a genetic mutation in a patient with Crigler-Najjar syndrome, type I. Hepatology. 15:941-947.

15. Johnstone, E. M., D. P. Smith, H. M. Hsiung, and S. P. Little. 1991. Direct sequencing of PCR products with TaQuence. In Editorial Comments. United States Biochemical Corp., Cleveland, Ohio. 18:22-23.

16. Geisselsoder, J., F. Witney, and P. Yuckenberg. 1987. Efficient site-directed in vitro mutagenesis. Biotechniques. 5:786-791.

17. Bansal, S. K., and T. Gessner. 1980. A unified method for the assay of uridine diphosphoglucuronyltransferase activities toward various aglycons using uridine diphospho[U- $\left.{ }^{14} \mathrm{C}\right]$ glucuronic acid. Anal. Biochem. 109:321-329.

18. MacKenzie, P. I., L. M. Hjelmeland, and I. S. Owens. 1984. Purification and immunochemical characterization of a low-pI form of UDP glucuronosyltransferase from mouse liver. Arch. Biochem. Biophys. 231:487-497.

19. Burchell, B., and M. W. H. Coughtrie. 1989. UDP-glucuronosyltransferases. Pharmacol. \& Ther. 43:261-289.

20. Sheen, Y. Y., F. Chen, O. W. McBride, J. K. Ritter, A. Dardowsky, and I. S. Owens. 1990. Evidence that two human liver cDNAs encode UDP-glucuronosyltransferase activity which differ by two logs. FASEB (Fed. Am. Soc. Exp. Biol.) J. 4:1774a. (Abstr.)

21. van Es, H. H. G., B. G. Goldhoorn, M. Paul-Abrahamse, R. P. J. Oude Elferink, and P. L. M. Jansen. 1990. Immunochemical analysis of uridine diphosphate-glucuronosyltransferase in four patients with the Crigler-Najjar syndrome type I. J. Clin. Invest. 85:1199-1205.

22. Owens, I. S., and J. K. Ritter. 1992. The novel bilirubin/phenol UDP-glucuronosyltransferase $U G T 1$ gen locus: implications for multiple nonhemolytic familial hyperbilirubinemia phenotypes. Pharmacogenetics. 2:93-108. 